\title{
DATA SCIENCE ASSESSMENT IN EXPLORATION OF RADIOACTIVITY AND URANIUM DISTRIBUTION AT SUUJIN TAL STRUCTURE IN SOUTH-EAST MONGOLIA
}

\author{
Boris Vakanjac \\ Enviroment and sustainable \\ development studies, \\ Singidunum University, \\ Belgrade, Serbia
}

\begin{abstract}
:
Suujin tal structure can be recognized from $500 \mathrm{~km}$ in height by looking at Google Earth or SASPlanet orthophoto satellite imagery. The center of the structure is located $170 \mathrm{~km}$ north of Mongolia's southern border with China. It was developed on the central Mongolian fault. This tectonic activity created the Suujin tal structure, as well as some other objects such as the Han Bogd granite intrusion, Zuunbayan valley, Naarst uplift and other. Part of the aforementioned fault intersects Suujin tal in the direction of SSW-NNE in an almost straight line over $50 \mathrm{~km}$. Within this area are historical radioactive anomalies 2453/529, 2453/530, 2453/531, 2453/511, 2453/512, and 2453/513 which were discovered by Soviet geologists during explorations carried out from 1979 - 1981. During a recent study of uranium at this site, a database was established, which include: raster and vector data - various maps, historic points of registered anomalies, recent field observation points, radioactivity measuring, airborne survey data, documentation photographs, and others[1]. In this paper, the main principles of procedures for mapping and database designing, which are using in this kind of explorations, will be presented.
\end{abstract}

Keywords:

radioactivity, tectonic activity, fault, Mongolia.

\section{INTRODUCTION}

The main objective of exploration activities at Suujin tal (Figure 1) was to find a uranium deposit. East and south-east Mongolia is, by its geological constitution, the potential for sediment-hosted uranium deposits. The bottom line is that Paleozoic granites and metamorphic rocks have been developed in this area, which by tectonic - uplift mechanism, build blocks that move conditionally "up" and graben systems built by blocks that descend. Granite and metamorphic rocks are decomposed by atmospheric conditions during millions of years and this material is deposited in descending systems. In this particular case, these are continental sedimentary processes and systems [2].

Granites worldwide (as well as their effluent equivalents rhyolite) carry uranium, thorium, and other radionuclide components. When decomposing these rocks in mild acids or bases, the stem (IV) uranium ion transfers to the migratory (VI) uranyl ion.
Correspondence:

Boris Vakanjac

e-mail:

bvakanjac@singidunum.ac.rs 
Uranyl ion is transferred to surface and groundwater through the environment in an oxidizing environment (soil or soil colors are yellowish, reddish, brownish, etc.). When it encounters a reducing medium (sediment colors are gray, black, gray-bluish, greenish, or almost white) or so-called. redox. The uranyl ion usually carried by watercourses goes into insoluble uranium ion and thus forms concentrations at the boundary of oxidation and reduction conditions[3].

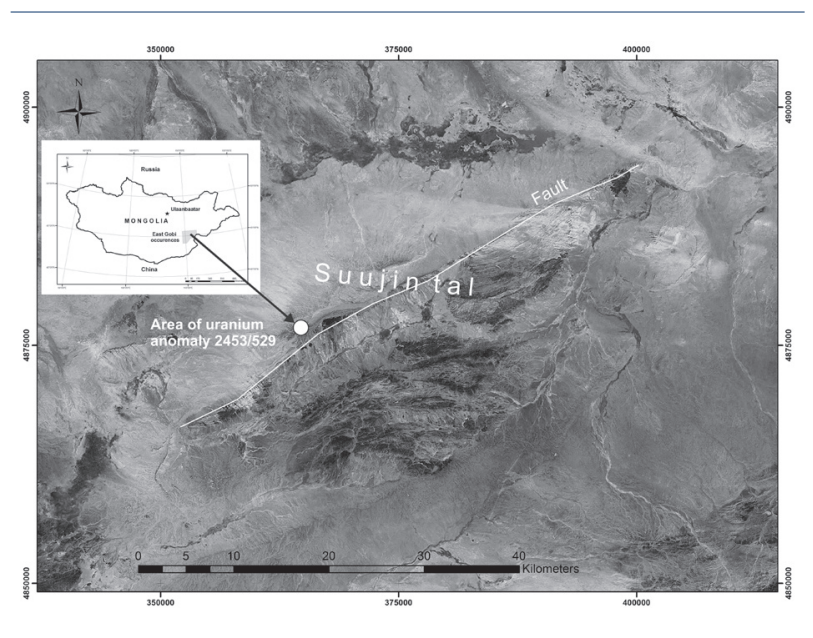

Fig. 1. Position od Suujin tal structure, radioactive anomaly 529 and fault line.

Groundwaters flowing through the sedimentation systems, which are influenced by intensive tectonics, carry different dissolved components. During tectonic movements, the positions of redox boundaries change place, and consequently uranium concentrations "travel" along with predisposed tectonic directions following the positions of the redox barrier.

The Suujin tal area has all characteristics for finding potential uranium deposit. In the far northeast of the structure were discovered two uranium deposits Dulaan ul [4] and Zovich Ovoo [5].

Based on historical Soviet data, and upon the establishment of an integral database of known positions and features of anomalies and zones, exploratory work was started in the area of interest.

\section{METHODOLOGY}

Investigative works were followed by methods of storing information in spatial databases.

Establishing a database system took several stages with is in close relation with operation exploration phases:
1. Collection and systematization of historical data;

2. Preparation of field research

3. Conducting field research

4. Airborne gamma survey

5. Organization of the final database and formation of layout.

\section{Geology settings of Suujin tal structure}

In historical data Suujin tal - it's a north-west part, is composed of the early Cretaceous huh teeg (K1ht) formation and late Cretaceous bayan shiree (K2bs) formation. During detail field geological exploration in July 2008 (mapping in scale 1:10.000, radiometric assaying, petrological and geochemical sampling) both sediment batches were explored in aim to define uranium distribution in a particular formation. In two layers of huh teeg (K1ht) formation, uranium grade is low - less than $10 \mathrm{ppm}$, but in sediments of bayan shiree (K2bs) formation uranium grade relatively high - up to 90 $\mathrm{ppm}$. The main uranium content is in sub-layer built of medium-grained loose gravel conglomerate, brown to reddish-brown, strongly oxidized, and slightly silicified. This uranium potential layer is situated in the southeast part of the explored area, with a fall towards the north at an angle of 10 to $30^{\circ}$, rarely 40 to $50^{\circ}$. Uranium bearing sediment complex is thick mainly 5 to $10 \mathrm{~m}$ and rarely up to $50 \mathrm{~m}$. During detailed mapping of uranium-bearing bayan shiree ( $\mathrm{K}_{2} \mathrm{bs}$ ) formation three layers were defined. Uranium was concentrated in the middle layer (medium-grained loose gravel conglomerate). In the lower muddy brown and upper reddish sandy layer, uranium was not found. Also, it was estimated that the bayan shiree (K2bs) formation which falls to the north, might create a synclinal structure, in which trenching and drilling should carry out, for possible uranium deposit, which is presumably is developed under the upper red sandy layer [6].

\section{Collection and systematization of historical data}

From the early 1950s to the end of the Soviet Union as coherent a state, intensive research was carried out in Mongolia by Soviet geologists and other experts from the states of the in that time existing Warsaw Pact. An enormous amount of data has been collected in the form of reports and studies stored in the territory of the present Russian Federation, and part of this material is also located in Mongolia at an institution called the Mongolian Mineral Resources Authority (MRAM). 
Suujin tal space is described in the Reports of Airborne gamma and geological surveys No 2453 [7] and No 2428 [8] (MRAM nomenclature). In the mentioned reports, besides geological description, the results of geophysical radiometric and geochemical testing, there are also catalogs of radioactive anomalies that were translated from Russian into English and organized in an excel database. From this material, shapefiles were generated - points with attributes that represent radioactive anomalies as points and polygons which representing the zones, both with the following attribute which describes anomalies and zones.

These reports include geological maps as well as airborne radioactivity survey maps given as four maps: distributions of gamma counts, uranium distribution, thorium distribution, and potassium distribution. The maps were scanned, georeferenced, and organized into a system along with topographic maps in scale 1: 100,000 and base geological maps in scale 1: 500,000. The maps show spaces covered by specific areas of Soviet explorations. Upon the establishment of a preliminary database of historical data, areas of interest were identified that needed to be processed by field activities and sampling.

Example of historic data in Excel sheet:

- Soviet number of anomaly - 529;

- Soviet Report number MRAM nomenclature 2453 O`ndurshil;

- Location - Unegetiin valley, Cagan-Suburgin plate $1,7 \mathrm{~km}$ from trigonometric point $979,7 \mathrm{~m}$;

- Latitude - 44.03611;

- Longitude - 109.32667;

- Uranium grade range $10^{-4} \%$ - $62 \mathrm{U}, 8 \mathrm{Th}, 4 \% \mathrm{~K}$;

- Geology setttings - Anomaly is situated in fractured fault zone of Cagan Suburgin plate, strongly limonitic sandstone which is over conglomerate-clay layer; Dimensions - $0.5 \mathrm{~m}$ thick layers in conglomerate at plate of 500 to $600 \mathrm{~m}^{2}$;

- Potential status - Anomaly is prospectiv sign for uranium ore;

- Associated elements in \% - 0.0001 to $0.011 \mathrm{Th}$, 0.037 to $0.080 \mathrm{~Pb}, 0.015 \mathrm{As}$;

- Background radioactivity in $\mathrm{mcr} / \mathrm{h}-20$;

- Radioactivity at anomaly - 30-62;

- Origin - secondary/sedimentary.

Thus, when preparing and processing historical data, the following was generated: Raster data in the following folders: Topographic maps 1: 100,000, Geological Maps
1: 500,000, Mineral map 1: 200.000. Shapefiles in folders: Uranium anomalies - points and Uranium anomalies zones.

\section{Preparation of field activities data}

Accessing anomalies, especially 2453/529, turned out to be a logistically complex task because the anomaly could not be easily reached. We have known from experience that there is always a path or at least a trace to Soviet trigonometric points that were set up during the late 1940s and 1950s; however, the space is empty and not suitable for traditional Mongolian nomadic livestock farming. Considering that from 1957 to 2007/8 is 50 years of erosion. Still, the challenge was great. At the time of these activities - fall 2007, no detailed orthophoto images were available as today (2020). We had topographic maps 1: 100,000 with roads connecting the cities Khuvsgul and Sainshand (bigger settlements in the area), at a distance of $150 \mathrm{~km}$. On the topographic map was a road connecting two springs, one at the point where it would have to turn from the Huvsgul - Sainshand direction in the northwest to reach another spring that was in the area ofinterest. There were multiple attempts and all were unsuccessful. I participated in two, where in the second attempt we tried to "catch" the edge of horst, from the northeast of the structure, which is built of solid rocks, however, it was not possible to pass to the structure because the area between road and horst was filled with loose sand.

The conclusion was that we have to pass from the southeast side, built of Paleozoic metamorphic rocks, and carefully study the available satellite imagery. After considerable effort, a route with checkpoints was established. It was less than 20 kilometers - from a turn off the main road to the Soviet trigonometric point orientation target, which we need to reach. With numerous stops, using GPS, a compass, printed satellite images, frequent stops, and pedestrian controls, we were able to reach the Soviet trigonometric point and anomaly 2453/529. After that, we made a GPS route and with this are possible to reach all points of interest. Following that, it was decided to establish a temporary yurt camp in the area of Suujin tal, with 4 geologists and two vehicles.

\section{Fieldwork data}

With the establishment of the driveway and temporary base, intensive measurement with the Exploranium GR135 Radiation Identification Device, mapping, and sampling began. Also, cross-sections and distribution of characteristic geological units of interest have been observed and mapped. 
The structures that traverse this area and divide it into the south-east and north-west are precisely defined. All observation points and the structure mentioned are in the field database as shapefiles. At the contacts along the fault, a large number of points with elevated radioactivity (over 200cps) exist.

In the northwestern part of K1ss and partly K2bs, and along the spreading zone, a large amount of petrified and silicified bones (Figure 2) was found whose radioactivity was once up to $1200 \mathrm{cps}$. It turns out that the anomaly $2453 / 529$ is the space where a silicified and fossilized tree was found with measured radioactivity of $700 \mathrm{cps}$ in an area of $20 \mathrm{~m}^{2}$ approx. in size.

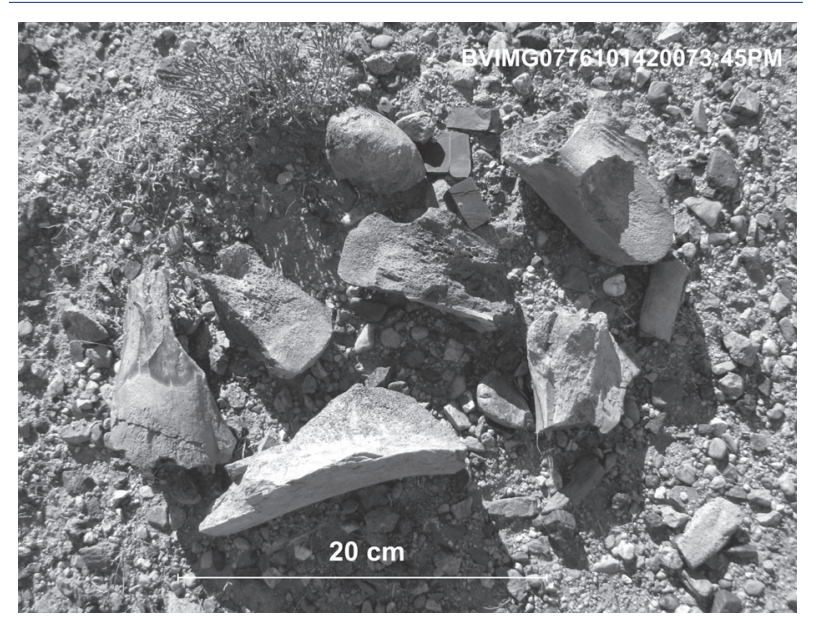

Fig. 2. Petrified and silicified bones with high radioactivity (up to $1200 \mathrm{cps}$ ).

During field research, the following data were generated:

- Raster data in next folders: Raster of the explored area - fact map in scale 1:100.000, Raster of the explored area on a digitized geological map 1 : 100,000 , Excel data of observation points.

- Vector data in the following folders: Observation points fact data with coordinates, Radioactivity values in observation points with coordinates, Samples used for chemical assaying.

- Text data: Report which describes geological units, distribution character of $\mathrm{U}, \mathrm{Th}, \mathrm{K}$ and total count in cps, field diary, and a proposal for further work. Below is given the example of observation point in with photo documentation.
Example of Field work data in Excel sheet:

- Observation point No-198;

- Area - 8530X; Datum (ellipsoid) - WGS84;

- UTM Zone-49T;

- Easting - 368902m;

- Northing - 4878431m;

- Latitude - 44.047328;

- Longitude - 109.363548;

- Radiometric Assay No - 1121;

- $\mathrm{K}(\%)-5.6$;

- $\mathrm{U}(\mathrm{ppm})-34.0$;

- Th (ppm) - 11.0;

- TOT count (cpm) - 1519;

- $\mathrm{K}(\mathrm{cpm})-286$;

- $\mathrm{U}(\mathrm{cpm})-128$;

- Th (cpm) - 12;

- BGS (cps) background radioactivity - 530,

- Description - reddish-brown conglomerate cemented with fine-grained siltstone fragments, thickness 0,8m, strike and dip a345/15-200;

- Photography No - 226; Elevation - 954m;

\section{Airborne gamma survey data}

Potential spaces were explored during May and June 2007 by airborne survey methods by contractor company Geosan LLC. A Cessna Caravan with two RSX-4 Gamma-Ray Spectrometers was used to measure radioactivity. The area of Suujin tal was numbered as Area 6. The distance between the routes was about $1000 \mathrm{~m}$; the average height was about $200 \mathrm{~m}$ depending on the situation. The data processed indicate that the areas with the highest radioactivity are in places that is water under the sand and on a ridge.

During the Airborne gamma survey the following types of data were established:

- Numerical database;

- Shapefile database;

- Generated maps: Total gamma distribution map in cps (count per second), Uranium counts distribution map, Thorium counts distribution map and Potassium counts distribution map and

- Text files: Report of the airborne survey [9]. 


\section{Organization of the final database}

The final database is a coherent system from which is possible to generate Layout/maps, Numerical data, and values, Reports as text data, Define potential for a deposit, and future exploration estimation of costs. The schematic organization (algorithm) is shown in Figure 3.

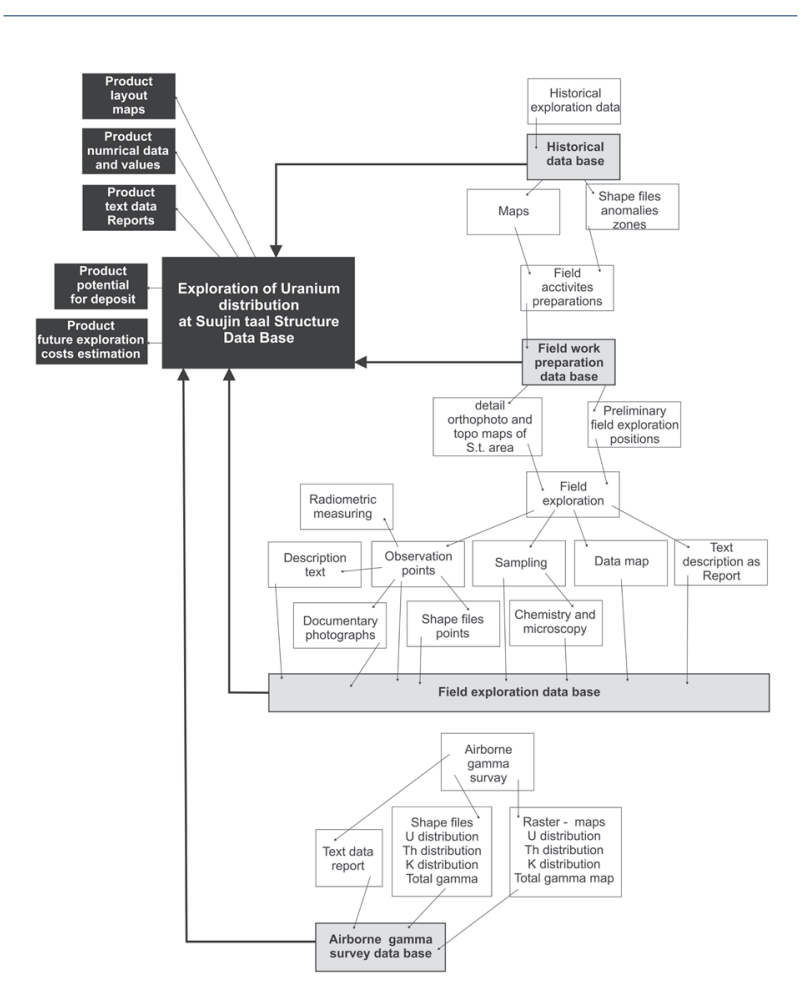

Fig. 3. Algorithm of final data base

\section{CONCLUSION}

When we started exploring the Suujin tal area, the main goal was an attempt to find a uranium deposit. After the first visit, I realized that the deposit may exist in the zone below the Quaternary sands in the central and northern part of the exploration License, below the Quaternary sediments, in Cretaceous package. The terrain is complex and possible drilling would be feasible, but with great effort. Instead of looking for uranium, this area should be protected as a world geological heritage. The fact is that it is a remote area, and it is not easy to get there, however, the presence of various rocks, faults, sediments, fossils, and other geological objects and features in a relatively small area is exceptional.

\section{ACKNOWLEDGMENT}

On this occasion, I would like to give great recognition to my Mongolian colleagues geologists Nurguli Raashkhan and Byambadrakh Bayarsaikhan.

\section{REFERENCES}

[1] B. Vakanjac, P. Srna, V. Ristić Vakanjac, "Establishment of a database of uranium anomalies and zones in Mongolia”, 161 - 168, September 2014. [Uranium - Past and Future Challenges, B.J. Merkel and A. Arab Eds. Springer, Freiberg, Proceedings of the $7^{\text {th }}$ International Conference of Uranium Mining and Hydrology]

[2] Yu.B. Mironov, "Uranium of Mongolia", Translated by Victor S. Popov, Centre for Russian and Central EurAsian Mineral Studies (CERCAMS), Natural History Museum, London, 2003/2005.

[3] N.F. Rutherford, "Uranium Deposits: Geochemistry, Radiometrics and Models b". Notes to accompany workshop presented to: Batu Mining Monolia LLC and Gobi Coal and Energy LLC, Ulaanbaatar 94 p. September 2006.

[4] https://www.mindat.org/loc-297435.html

[5] https://www.mining.com/areva-discovers-big-uranium-deposit-in-mongolia-23178/

[6] N. Raashkan, "Monthly report (Geological formation and mineral recourses of Suujin tal 8530X", Zaraiya Holdings LLC. Ulaanbaatar, p 4, 2008.

[7] Yu. S. Shmelev, V.I. Panev, Yu.M. Gavrilov, V.D. Tataurov, A.V. Evstigneev, "Report on air geophysical and geological mapping at scale 1:200.000 carried out on O'ndorshil area”, Ministry of Geology USSR, "Zarubezgeologya", Mongolian GeologicalSurveying Expedition, South Group. (MRAM No 2453) Legend, 12 p. Sverdlovsk. 1982.

[8] U.V. Troitskii, V.A. Kaldishkin, V.S. Kormilicin, T.V. Kaldashkina, Report on Prospecting-Exploration on Uranium in East Gobi Area for 1978-1980" (Geological assingment MGSE-15), Ministry of Geology USSR, "Zarubezgeologya", Mongolian Geological-Surveying Expedition. (MRAM No 2428), p76-81 and p171-217. 1981.

[9] Geosan, Logistic Report, Mongolia Dornogovi Aimag, Sainshand Airborne Geophysical Srvey, August - September 2008 for Zaraiya Holdings LLC, p 1 - 9, 2008 